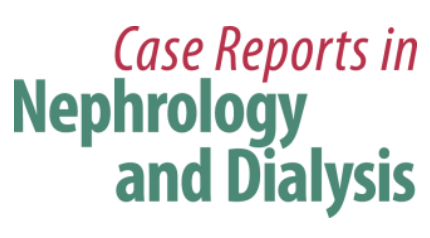

\title{
Embolization of Spontaneous Intratumoral Hemorrhage with the Hemodynamic Characteristics of Arteriovenous Fistula in Renal Angiomyolipoma
}

\author{
Nao Kikuchi Ryohei Kuwatsuru Shinsuke Kyogoku Akihiko Shiraishi \\ Shingo Okada Daisuke Tsuge Yuki Yamashiro \\ Department of Radiology, Faculty of Medicine, Juntendo University, Tokyo, Japan
}

\section{Key Words}

Aneurysm · Angiomyolipoma $\cdot$ Embolization $\cdot$ Kidney $\cdot$ Rupture

\begin{abstract}
Aneurysms within renal angiomyolipomas (AML) may rupture into the tumor or pararenal space. Transcatheter arterial embolization is the first-choice treatment to control bleeding. Here, we describe the use of coil embolization in two cases of spontaneous intratumoral hemorrhage with the hemodynamic characteristics of renal arteriovenous (AV) fistula in renal AML. In case 1 , renal angiography showed several intratumoral aneurysms, one of which had ruptured into the tumor, resulting in the formation of an intratumoral hematoma. Blood flow within the hematoma was rapid and the blood was immediately returned to the systemic circulation through the left renal vein. In case 2, renal angiography showed that the rupture of an intratumoral aneurysm of a tumor-feeding artery had resulted in formation of an intratumoral hematoma and direct renal vein communication. No extratumoral hemorrhage was observed in either case. The hemodynamics of both hematomas resembled those of a highflow renal AV fistula. The ruptured aneurysms were embolized with detachable and pushable coils (case 1 ) or pushable coils only (case 2). To our knowledge, this is the first report of successful embolization of AV fistula-like intratumoral hemorrhage in renal AML.
\end{abstract}




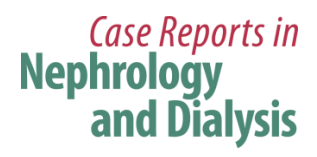

Case Rep Nephrol Dial 2015;5:54-59

DOI: $10.1159 / 000371844$

(c) 2015 S. Karger AG, Basel

www.karger.com/cnd

Kikuchi et al.: Embolization of Spontaneous Intratumoral Hemorrhage with the Hemodynamic Characteristics of Arteriovenous Fistula in Renal Angiomyolipoma

\section{Introduction}

Treatments for intratumoral hemorrhage in renal angiomyolipoma (AML) include nephron-sparing surgery, radical nephrectomy, and transcatheter arterial embolization [1].

Superselective coil embolization is an effective, minimally invasive procedure for the treatment of intratumoral hemorrhage in AML from the perspectives of stopping bleeding and preserving the normal renal parenchyma. However, it remains unknown which is the most appropriate embolization material to use when the hemodynamics of a ruptured aneurysm resemble those of a high-flow renal arteriovenous (AV) fistula due to direct communication with the renal vein.

\section{Case Reports}

Case 1

A 38-year-old woman developed acute, severe pain from the left neck to the lower back during exercise. The pain gradually decreased without treatment. Twelve days later, fever developed and the back pain returned. She underwent a medical examination and was treated conservatively. However, because her C-reactive protein level remained high and the back pain persisted she was referred to our hospital.

Upon admission, she described pain radiating from the left lower back to the shoulder and physical examination revealed a large, tender, palpable mass between the left subcostal region and the iliac crest. She was conscious and had conjunctival signs of anemia. Breath sounds in the left lung were weak. Her vital signs were as follows: blood pressure, 110/64 $\mathrm{mm} \mathrm{Hg}$; heart rate, 78 beats $/ \mathrm{min}$, and body temperature, $38.8^{\circ} \mathrm{C}$.

Laboratory investigations showed white blood cell count, 7,100/ $\mu$; red blood cell count, $2.73 \times 10^{6} / \mu \mathrm{l}$; hemoglobin, $8.5 \mathrm{~g} / \mathrm{dl}$; platelet count, $280 \times 10^{3} / \mu \mathrm{l}$, and hematocrit, $25.9 \%$. She had no other significant medical history, including no history of tuberous sclerosis.

Contrast-enhanced CT showed a retroperitoneal mass $(15 \times 10 \times 10 \mathrm{~cm})$ protruding from the left renal upper pole with fat attenuation suggesting AML (fig. 1a). An intratumoral hematoma measuring $7 \mathrm{~cm}$ in diameter was equally enhanced with the artery during the arterial phase of a dynamic study.

Immediate left renal angiography revealed a tumor reaching from the left renal upper pole to the middle pole. The arteries feeding the AML originated from the upper pole branches of the left renal artery and contained several aneurysms. The outermost aneurysm had ruptured into the tumor, causing an intratumoral hematoma to form (fig. 1b). The blood flowed counter-clockwise within the intratumoral hematoma and moved from the hematoma to the left renal vein and inferior vena cava in a manner that hemodynamically resembled a high-flow renal AV fistula (fig. 1c). Contrast medium did not leak outside the tumor.

A microcatheter was placed close to the ruptured aneurysm for superselective embolization. In total, we placed 13 ( 3 of $5 \mathrm{~mm} \times 10 \mathrm{~cm}, 8$ of $4 \mathrm{~mm} \times 8 \mathrm{~cm}$, and 2 of $3 \mathrm{~mm} \times 8 \mathrm{~cm}$ ) Guglielmi Detachable Coils (GDC ${ }^{\circledR}$; Stryker, Kalamazoo, Mich., USA), five $3 \times 2 \mathrm{~mm}$ pushable coils (VortX ${ }^{\circledR} 18$ Diamond Shaped Fibered Platinum Coils; Boston Scientific Corporation, Boston, Mass., USA), and seven $3 \times 2 \mathrm{~mm}$ pushable coils (Tornado ${ }^{\circledR}$; Cook Medical Inc., Bloomington, Ind., USA) in the ruptured aneurysm and feeding artery, and placed the coils as tightly as possible to stop extravasation.

Left renal arteriography after embolization showed only minor leakage into the hematoma and no embolization of the normal renal parenchyma (fig. 1d). No further embolizations were performed because the minor leakage was too small for the embolization to be 


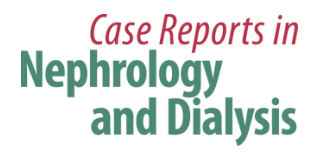

\begin{tabular}{l|l}
\hline Case Rep Nephrol Dial 2015;5:54-59 \\
\hline DOI: $10.1159 / 000371844$ & $\begin{array}{l}\text { C 2015 S. Karger AG, Basel } \\
\text { www.karger.com/cnd }\end{array}$ \\
\hline
\end{tabular}

Kikuchi et al.: Embolization of Spontaneous Intratumoral Hemorrhage with the Hemodynamic Characteristics of Arteriovenous Fistula in Renal Angiomyolipoma

effective. Furthermore, since an arterial branch to the normal renal parenchyma was located close to the proximal embolization, additional embolization may have affected the normal renal parenchyma.

Arterial bleeding was not evident on abdominal CT at 4 days after the embolization. The CT numbers in the hematoma did not increase at any phase of a dynamic contrast study, suggesting the absence of leakage from the embolized aneurysm into the tumor. The patient was discharged 10 days after embolization and her clinical course was uneventful.

Case 2

A 66-year-old woman developed low-grade fever that persisted for 10 days. Despite taking medication prescribed by her local clinic, after 1 week the fever had increased to $>38^{\circ} \mathrm{C}$ and left flank pain had developed, so she was referred to our hospital.

Upon admission, she described left flank pain and abdominal fullness. Physical examination revealed a well-demarcated tender tumor in the left flank. She was conscious and had no conjunctival signs of anemia. Her vital signs were as follows: blood pressure, 136/78 mm $\mathrm{Hg}$; heart rate, 93 beats $/ \mathrm{min}$, and body temperature, $37.9^{\circ} \mathrm{C}$. Laboratory investigations showed white blood cell count, $12,000 / \mu \mathrm{l}$; red blood cell count, $3.74 \times 10^{6} / \mu \mathrm{l}$; hemoglobin, $11.1 \mathrm{~g} / \mathrm{dl}$; platelet count, $344 \times 10^{3} / \mu \mathrm{l}$, and hematocrit, $37.4 \%$. She had no other significant medical history, including no history of tuberous sclerosis.

Abdominal three-dimensional CT angiography image showed a large left renal AML (12 $\times 11 \times 9 \mathrm{~cm}$ ) containing a ruptured intratumoral aneurysm that was producing both an intratumoral hematoma (fig. 2a) and an AV fistula with early venous return. Left renal angiography confirmed the presence of a ruptured intratumoral aneurysm creating the AV fistula (fig. 2b).

As the AV fistula was small, we placed $20(10$ of $3 \times 2 \mathrm{~mm}, 4$ of $4 \times 2 \mathrm{~mm}, 5$ of $5 \times 2 \mathrm{~mm}$, and 1 of $6 \times 2 \mathrm{~mm}$ ) pushable coils (Tornado ${ }^{\circledR}$; Cook Medical Inc.) in the ruptured aneurysm and tumor-feeding artery to stop the intratumoral bleeding and the AV fistula formation. An additional tumor-feeding artery was embolized with Gelpart ${ }^{\circledR}$ to reduce the tumor size. Left renal angiography after embolization showed that the ruptured aneurysm and AV fistula had been successfully embolized without embolization of the normal renal parenchyma (fig. 2c).

\section{Discussion}

Renal AMLs are common benign neoplasms composed of fatty tissue, smooth muscle, and blood vessels [2]. The precise pathogenic mechanism of this disease is unknown [3]. The reported prevalence of AMLs among the general hospitalized population in Japan is $0.31 \%$ [4]. Although most AMLs are asymptomatic, $68-80 \%$ of patients become symptomatic if the tumor reaches $\geq 4 \mathrm{~cm}$ in size [4]. The classic Lenk's triad of renal AML includes flank pain, a palpable tender mass, and signs of internal bleeding (e.g., hematuria) [2]. Renal AML rupture can result in life-threatening hypovolemic shock [2]. The most important factors governing AML rupture are aneurysm and tumor size [4]. Aneurysms are most likely to rupture if they are $\geq 5 \mathrm{~mm}$ in size and the tumor is $\geq 4 \mathrm{~cm}$ in size [4]. In the present report, case 1 was a $15 \times$ $10 \times 10 \mathrm{~cm}$ tumor with several 4 - to 9 -mm aneurysms, and case 2 was a $12 \times 11 \times 9 \mathrm{~cm}$ tumor with a 5-mm aneurysm. In both cases, one of the intratumoral aneurysms had ruptured and intratumoral arterial bleeding without extratumoral bleeding was evident.

Patients with a ruptured AML often present with acute pain as a result of hemorrhage, and $20 \%$ are in hypovolemic shock at the time of initial presentation [4]. Although the hemoglobin value was decreased in both patients presented here, neither were in hypovolemic 


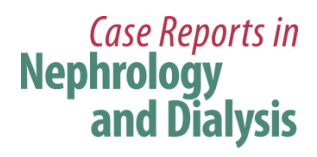

\begin{tabular}{l|l}
\hline \multicolumn{2}{l}{ Case Rep Nephrol Dial 2015;5:54-59 } \\
\hline DOI: 10.1159/000371844 & $\begin{array}{l}\text { ○ 2015 S. Karger AG, Basel } \\
\text { www.karger.com/cnd }\end{array}$ \\
\hline
\end{tabular}

Kikuchi et al.: Embolization of Spontaneous Intratumoral Hemorrhage with the Hemodynamic Characteristics of Arteriovenous Fistula in Renal Angiomyolipoma

shock because the hemorrhage was limited to the tumor and the blood was returned to the systemic blood flow either from the hematoma through the left renal vein (case 1) or through direct communication with the left renal vein (case 2).

The aneurysms were selectively embolized by using a microcatheter and either a stack of detachable and pushable coils (case 1) or pushable coils only (case 2). In both cases, the normal renal parenchyma was preserved by selectively embolizing the aneurysm (case 1) or the aneurysm and tumor (case 2). Thus, renal function was preserved.

Available embolization materials included polyvinyl alcohol foam powder (PVA) with coils [5], PVA with alcohol [6], alcohol with ethiodized oil [7], and sterile compressed sponge (Gelfoam ${ }^{\circledR}$, Pfizer Japan Inc.) [8]. The use of particle- or liquid-based embolization materials requires careful consideration because these materials can pass through the kidneys and tumor to the lungs. Pulmonary edema has been reported after embolization of a renal AML with alcohol and iodized oil [9]. Furthermore, particle- or liquid-based embolization materials are not suitable for treating ruptured AMLs because of the presence of AV fistula-like hemodynamics. Therefore, detachable and/or pushable coils are a more suitable option that allow compact, targeted embolization without the risk of causing pulmonary embolism.

In conclusion, transcatheter arterial embolization is an effective first-choice therapy for the treatment of spontaneous intratumoral hemorrhage in AML in terms of rapid hemostasis, minimal invasiveness, and preservation of renal function. Therefore, it is preferable to open or laparoscopic approaches such as tumorectomy and nephrectomy. Furthermore, careful observation of the hemodynamics of intratumoral ruptures is important before proceeding with transcatheter arterial embolization. In the case of ruptured tumor with AV fistula, the use of particle- and liquid-based embolization material should be avoided.

\section{Disclosure Statement}

The authors declare that they have no conflicts of interest.

\section{References}

1 Koo KC, Kim WT, Ham WS, Lee JS, Ju HJ, Choi YD: Trends of presentation and clinical outcome of treated renal angiomyolipoma. Yonsei Med J 2010;51:728-734.

2 Wang HB, Yeh CL, Hsu KF: Spontaneous rupture renal angiomyolipoma with hemorrhage shock. Inter Med 2009;48:1111-1112.

-3 Sugimoto T, Morita Y, Kashiwagi A: Spontaneous hemorrhage from renal angiomyolipoma presenting with fever of unknown origin. Inter Med 2007;46:793-794.

4 Yamakado K, Tanaka N, Nakagawa T, Kobayashi S, Yanagawa M, Takeda K: Renal angiomyolipoma: relationship between tumor size, aneurysm formation, and rupture. Radiology 2002;225:78-82.

-5 Mourikis D, Chatziioannou A, Antoniou A, Kehagias D, Gikas D, Vlahos L: Selective arterial embolization in the management of symptomatic renal angiomyolipomas. Eur J Radiol 1999;32:153-159.

-6 Zerhouni EA, Schellhammer P, Schaefer JC, Drucker JR, Jaffe AH, Gonzales JE, et al: Management of bleeding renal angiomyolipomas by transcatheter embolization following CT diagnosis. Urol Radiolgy 1984;6:205209.

7 Bishay VL, Crino PB, Wein AJ, Malkowicz SB, Trerotola SO, Soulen MC, et al: Embolization of giant angiomyolipomas: technique and results. J Vasc Interv Radiol 2010;21:67-72.

-8 Moorhead JD, Fritzsche P, Hadley HL: Management of hemorrhage secondary to renal angiomyolipoma with selective arterial embolization. J Urol 1977;117:122-123.

-9 Hiraki T, Mimura H, Gobara H, Fijiwara H, Iguchi T, Sakurai J, et al: Pulmonary edema as a complication of transcatheter embolization of renal angiomyolipoma in a patient with pulmonary lymphangioleiomyomatosis due to tuberous sclerosis complex. J Vasc Interv Radiol 2009;20:819-823. 


\section{Case Reports in \\ Nephrology \\ and Dialysis}

\begin{tabular}{l|l}
\hline \multicolumn{2}{l}{ Case Rep Nephrol Dial 2015;5:54-59 } \\
\hline DOI: 10.1159/000371844 & $\begin{array}{l}\text { ○ 2015 S. Karger AG, Basel } \\
\text { www.karger.com/cnd }\end{array}$ \\
\hline
\end{tabular}

Kikuchi et al.: Embolization of Spontaneous Intratumoral Hemorrhage with the Hemodynamic Characteristics of Arteriovenous Fistula in Renal Angiomyolipoma
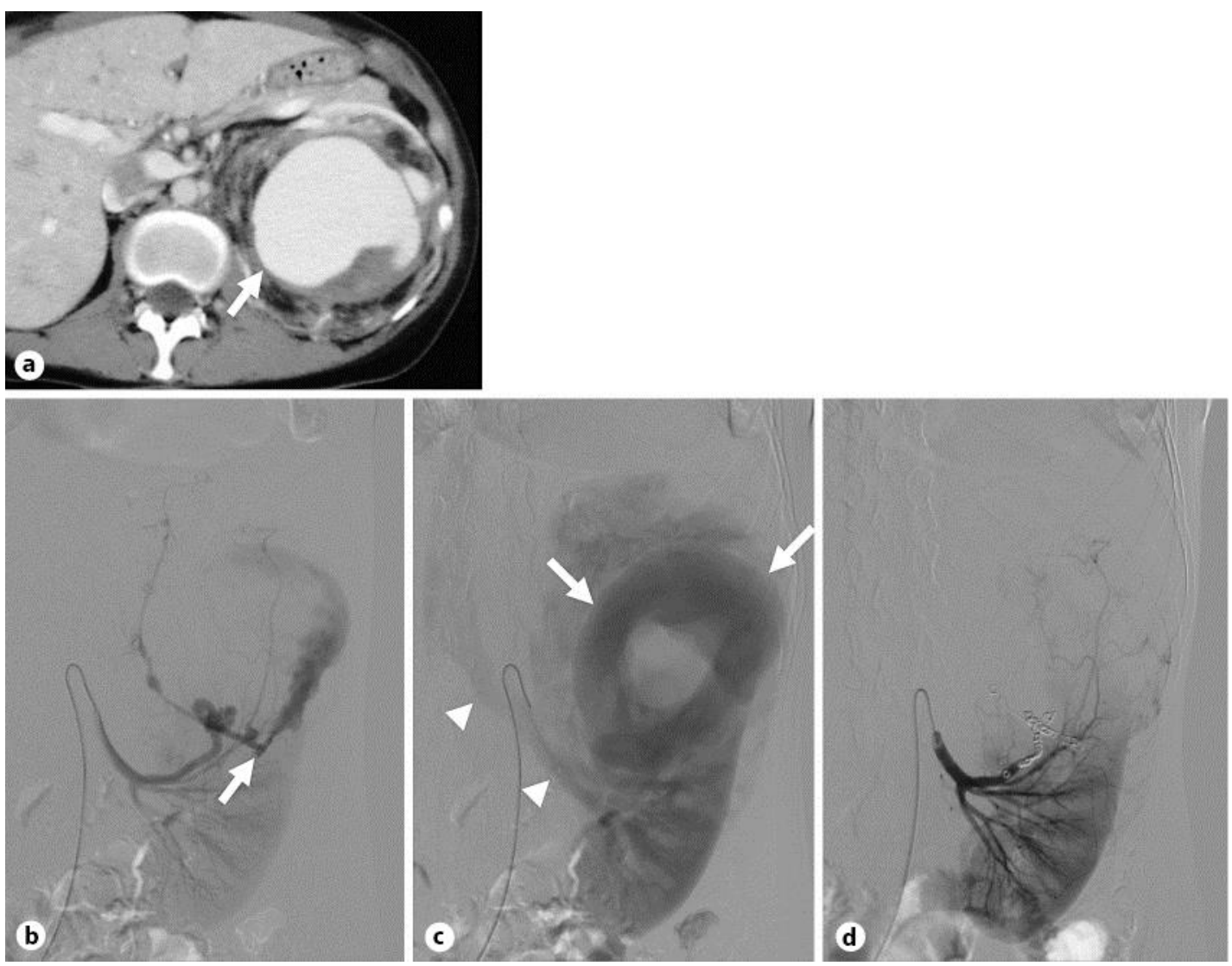

Fig. 1. a Abdominal contrast-enhanced computer-tomography image. A large tumor was observed in the left renal upper pole with fat attenuation suggesting AML. A massive intratumoral hemorrhage was visualized as an enhanced area (arrow). b Left renal angiography (early phase). The tumor-feeding branch of the left renal artery contained several aneurysms. The outermost aneurysm had ruptured and contrast agent was extravasated into the hematoma (arrow). c Left renal angiography (parenchymal phase). The hematoma was immediately filled with contrast agent that flowed counter-clockwise (arrows) and rapidly exited the hematoma via the left renal vein (arrowheads). $\mathbf{d}$ Left renal angiography after embolization. After embolization, angiography showed no evidence of arterial bleeding, hematoma, or early venous return. The normal renal parenchyma was preserved. 


\section{Case Reports in \\ Nephrology and Dialysis}

\begin{tabular}{l|l}
\hline \multicolumn{2}{l|}{ Case Rep Nephrol Dial 2015;5:54-59 } \\
\hline DOI: $10.1159 / 000371844$ & $\begin{array}{l}\text { C } 2015 \text { S. Karger AG, Basel } \\
\text { www.karger.com/cnd }\end{array}$ \\
\hline
\end{tabular}

Kikuchi et al.: Embolization of Spontaneous Intratumoral Hemorrhage with the Hemodynamic Characteristics of Arteriovenous Fistula in Renal Angiomyolipoma
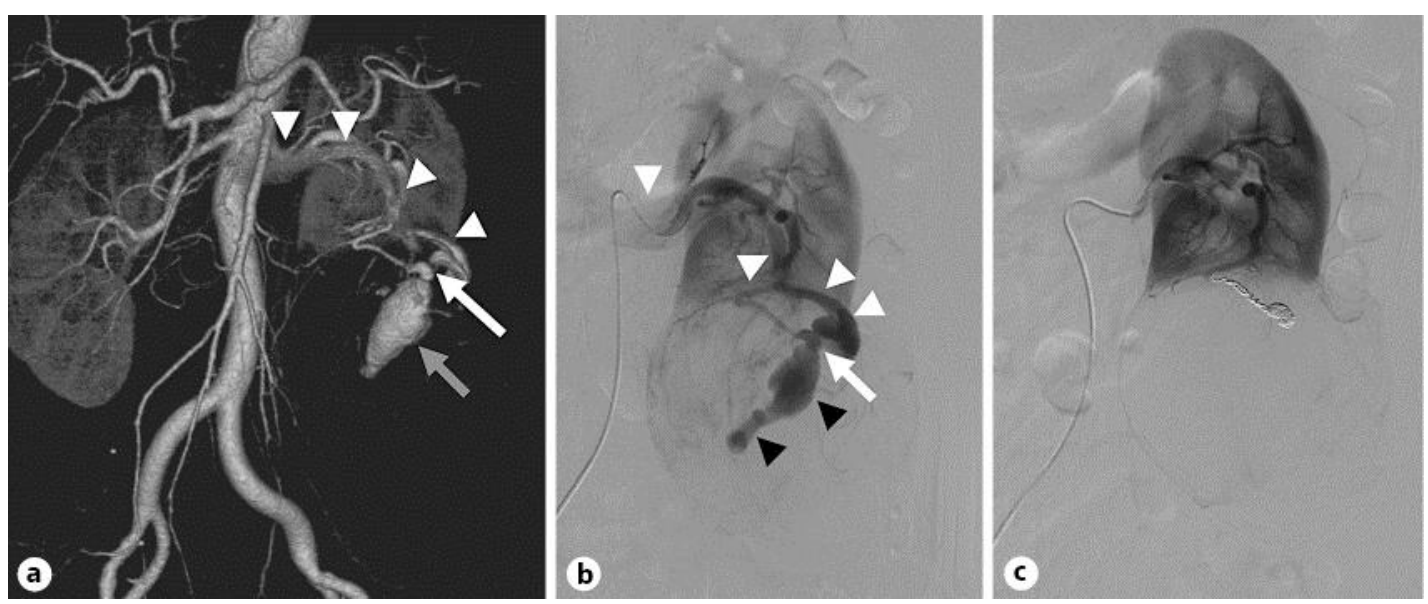

Fig. 2. a Abdominal three-dimensional CT angiography image. The tumor-feeding branch of the left renal artery with the aneurysm (white arrow). The aneurysm had ruptured both into the right side of the tumor, resulting in the formation of an intratumoral hematoma (gray arrow), and into the left side of a peritumoral vein, resulting in early venous return (white arrowheads). b Left renal angiography (early phase). An aneurysm of the tumor-feeding artery (white arrow) had ruptured both into the right side of the tumor, resulting in the formation of an intratumoral hematoma (black arrowheads), and into the left side of a peritumoral vein, resulting in early venous return (white arrowheads). c Left renal angiography after embolization. After embolization, the tumor, tumor-feeding artery, aneurysm, and AV fistula were not observed. The normal renal parenchyma was preserved. 